\title{
Clinical presentation and treatment of multifocal epitrichial sweat gland carcinoma in a horse
}

\author{
Cristóbal A. Dörnera* ${ }^{a *}$ Cristóbal H. Castellóna ${ }^{a}$ Diego Yañez ${ }^{b}$
}

\begin{abstract}
Epitrichial gland carcinoma is a very rare type of skin tumour in horses. This report describes a horse presenting multiple nodules with associated normal, alopecic and ulcerated skin diagnosed via histopathology as epitrichial gland carcinoma. Treatment consisted of combined surgical excision, topical therapy for ulcerated nodules and cryotherapy for non-ulcerated tumours. Six months following therapy, the excised masses had not regrown and only 10 out of 25 small tumours previously treated with cryotherapy were noticeable.

Key words: horse, skin, apocrine glands, neoplasia.
\end{abstract}

The skin is the most common site of neoplasia in the horse, representing about $50 \%$ of all equine neoplasms (Scott and Miller 2011 ${ }^{\mathrm{a}}$ ). Among the tumours affecting equine skin, sarcoid, melanoma, papilloma and squamous cell carcinoma have been the most frequently identified (Scott and Miller 2011 a , Hewes and Sullins 2009). Less common skin tumours such as basal cell (Slovis et al 2001), glomus (Burns et al 2011), myxomas, and mast cell tumours (Lykkjen et al 2006) have been also diagnosed. Epitrichial or apocrine sweat gland carcinoma is a very rare condition that has been reported very few times and represents $0.1 \%$ of skin neoplasms of the horse (Anderson et al 1990, Scott and Miller 2011 a, Cihocki et al 2007, Ghasami et al 2017). Sweat gland neoplasms are tumours arising from the glandular or ductal components of epitrichial sweat glands being commonly benign proliferations.

A 12-year-old crossbreed mare (Holsteiner x Selle Français) developed a large number of cutaneous masses extending from just distal to the carpus to the pastern of the right forelimb. The masses developed over six-months and, concurrently, the mare developed lameness of the right forelimb that did not improve with anti-inflammatory treatment (phenylbutazone ${ }^{1} 2.2 \mathrm{mg} / \mathrm{kg}$ IV BID for 5 days). On presentation, the mare was bright, alert and responsive. Twenty-five skin nodules distal to the carpus with associated normal, alopecic and ulcerated skin surfaces were present (figure 1A). The nodules varied in shape and size ranging from $0.5 \mathrm{~cm}$ to $2.5 \mathrm{~cm}$ diameter. The differential diagnoses included equine sarcoid, eosinophilic granuloma, and chronic proliferative pastern dermatitis ("grapes").

Received: 21.01.2020.

Accepted: 01.07.2020.

aEquestria Centro Médico Equino, Quillota, Chile.

bUniversidad de Viña del Mar, Viña del Mar, Chile.

Corresponding author: CA Dörner; Avenida Larraguibel S/N, San Isidro, Quillota, Chile; cdorner@gmail.com

1 Equs 10\%, Drag Pharma, Santiago, Chile
Three small masses were excised under standing sedation and were submitted for histopathological evaluation. None appeared to extend into the subcutaneous tissue grossly, and all of them were easily delimitated and removed. Submitted masses had similar histological features. Neoplastic cells were infiltrated in the dermis with formation of dense clusters with a glandular appearance (figure 2A, 2B). Trabecular, tubular and solid structures were observed with frequent central necrosis. Occasionally, luminal structures containing eosinophilic material were observed. Clusters were separated by fibrous connective tissue (desmoplastic stroma) (figure 2C). Neoplastic cells were cuboidal with eosinophilic cytoplasm with clearly defined borders. The cells presented round to oval, central and hyperchromatic nuclei with inconstant nucleoli (figure 2D), and 1-2 mitosis/ $\mathrm{x} 400$ microscopic field were observed. The final histopathological diagnosis was epitrichial sweat gland carcinoma.

Following excision, the surgical sites were closed using 2-0 polyglicolic acid suture, and the limb was bandaged. The ulcerated nodules were lavaged with Chlorhexidine $2 \%^{2}$ daily for two weeks, and silver spray ${ }^{3}$ was applied daily for two weeks. Antibiotic therapy with Procaine Penicillin G + Dihydrostreptomycin ${ }^{4}$ (12.000 UI/kg IM SID) for 10 days and Gentamicin ${ }^{5}$ (6.6 mg/kg IV SID) for 10 days was given to treat the presumed infection of the ulcerated skin of the palmar aspect of the pastern, and Flunixin Meglumine ${ }^{6}(1.0 \mathrm{mg} / \mathrm{kg}$ IV BID) was administered for 5 days to minimise pain and inflammation. Cryotherapy ${ }^{7}$ was used to treat the remaining non-ulcerated tumours. Cryotherapy was applied via a commercial system which uses dimethyl ether, propane, and isobutane to treat papillomas in humans. This system is an easy and ready-to-use

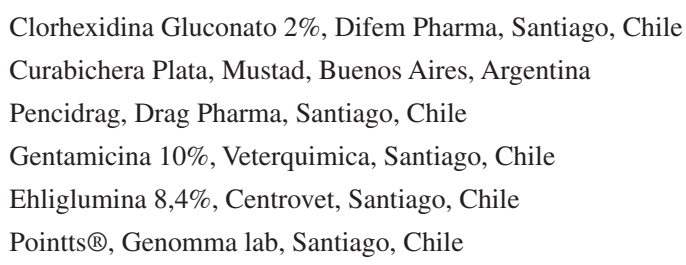




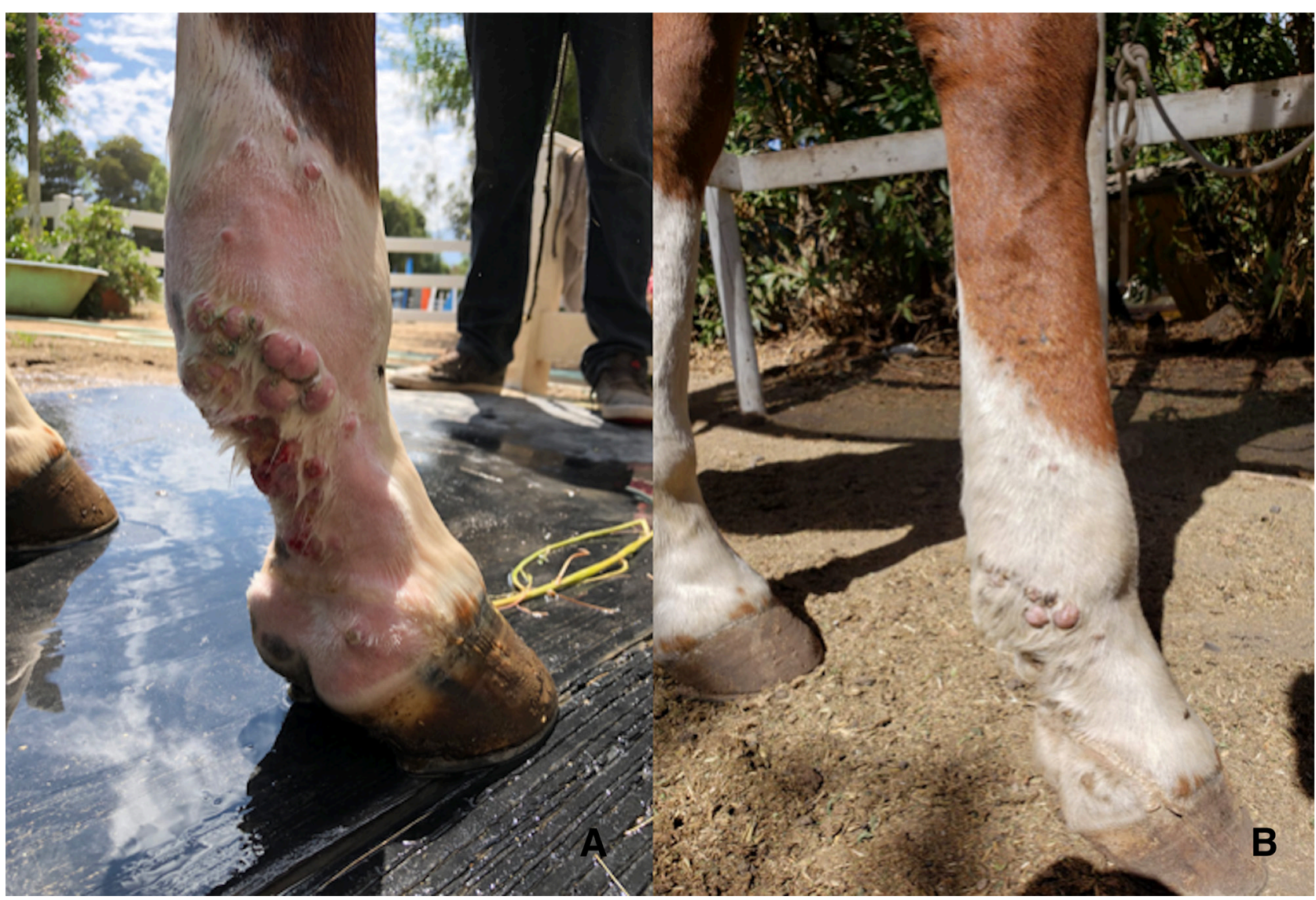

Figure 1. Right forelimb palmar fetlock and pastern of a 12-year-old mare. A) Multiple alopecic and ulcerated skin nodules; B) 1-month follow up after cryotherapy. Despite the presence of hair regrowth somewhat obscuring the complete visualisation of the masses in the photo, the larger nodules are significantly smaller, and many of the smaller tumours are undetectable.

product which consists of spray and sponge applicators that are applied directly over the affected skin according to manufacturer's instructions.

Re-examination one month after initialising the treatment showed that the ulcerated pastern skin had completely healed, and no lameness was evident. The surgery sites displayed no abnormalities, and normal scar tissue was present. The remaining 10 masses detectable after cryotherapy were smaller, and no new tumours were observed (figure 1B). Since improvement was noted and no adverse reactions nor abnormalities were detected during the initial treatment, a second course of cryotherapy was recommended but it was declined by the owner. Six months following therapy, the excised masses had not regrown, and only 10 out of 25 small tumours previously treated with cryotherapy were noticeable.

We described a case of epitrichial sweat gland carcinoma with a good outcome following treatment with excision, topical therapy, cryotherapy, and conservative medical therapy. The epitrichial sweat glands are distributed throughout all haired skin, and they are largest and most numerous in the submandibular region, mane, near the mucocutaneous junctions, and near the coronary band
(Scott and Miller 2011 ${ }^{\mathrm{b}}$ ). It is therefore unsurprising that the tumours described previously have been located in the genital tissue and pastern region. In our report, the fetlock region tumours were larger and more densely arranged, whereas the main characteristic of the pastern region tumours was ulceration. Finally, the tumours located in the metacarpal region were smaller and had normal or alopecic skin.

The presented case, although similar to those reported by Cihocki et al (2007) and Ghasemi et al (2017), is unique because of the variable nature of the lesions, the treatment selected and the tumour behaviour after treatment. Furthermore, since the location, type, and number of lesions in our case differs from previously described cases, this report adds to the knowledge of this rare and so far poorly understood type of tumour in horses.

The diagnosis was achieved by histopathology and was based on the appearance and description of epitrichial sweat gland carcinoma published in previous reports (Kalaher et al 1990, Cihocki et al 2007, Ghasemi et al 2017). All samples had the same architecture suggesting that one tumour may spread throughout the limb. Although haematogenous or lymphatic spread has been suggested 


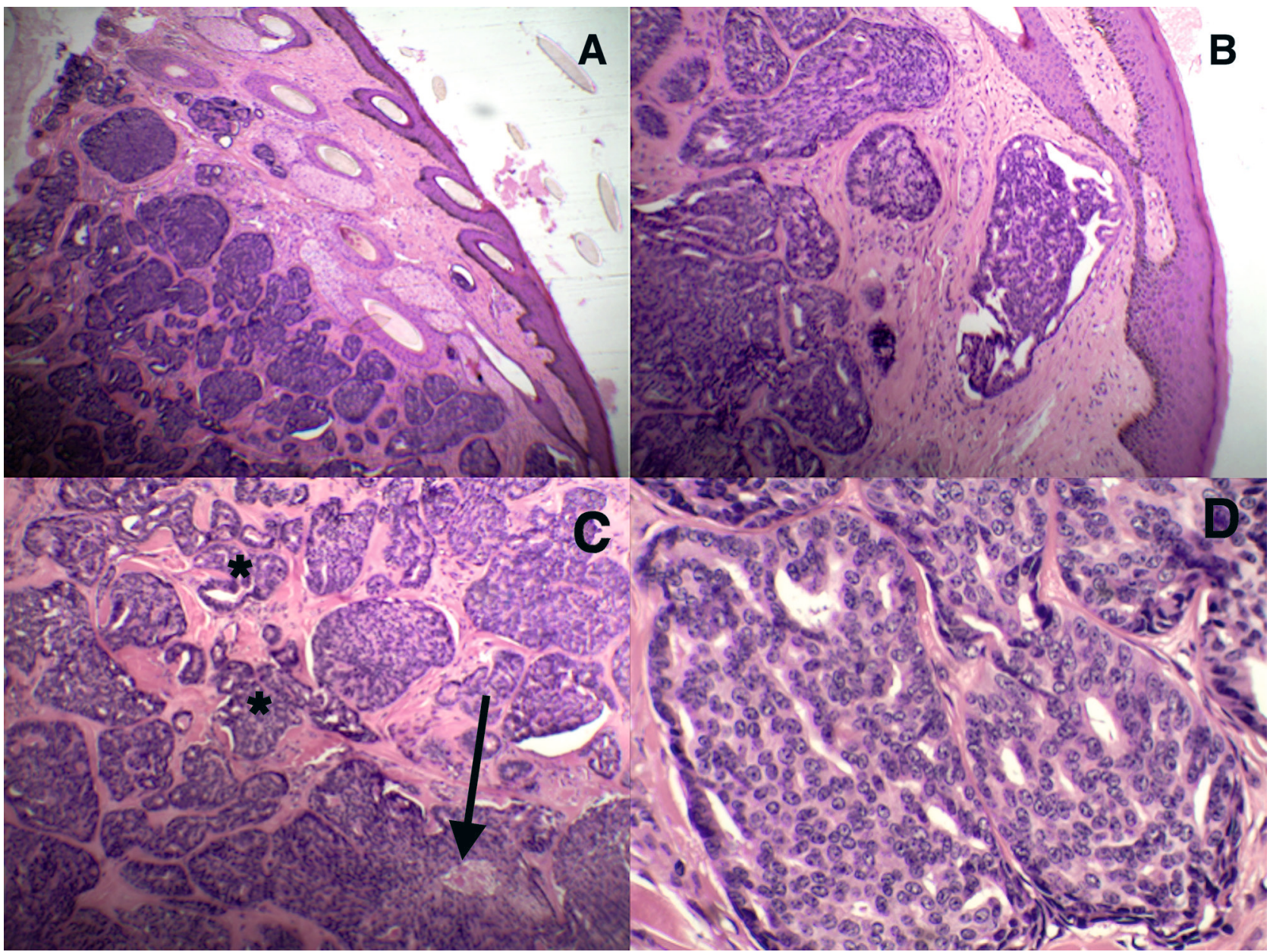

Figure 2. Histological sections of a skin nodule obtained from the fetlock area of the right forelimb, haematoxylin and eosin stain. A) Neoplastic cells infiltrated into the deep dermis (10x); B) Densely packed clusters of neoplastic epitrichial sweat gland cells demonstrate irregular, infiltrative growth (40x); C) Poorly demarcated and infiltrative clusters of neoplastic cells form numerous tubular (ducts) (*), trabecular and solid structures, the clusters are separated by fibrous connective tissue (desmoplastic stroma). A focal area of necrosis is present within one cluster (arrow) (100x); D) Note the presence of cuboidal cells with eosinophilic cytoplasm in the neoplastic glandular epithelium, the cells contain round to oval central and hyperchromatic nuclei with inconstant nucleoli (400x).

in humans, dogs and cats (Kalaher et al 1990, Simko et al 2003, Tlemcani et al 2010, Jark et al 2015), to date there is no evidence supporting that notion in horses. The mechanism of spread is still open for discussion given that some authors report that apocrine neoplasias have invasive behaviour, and they can metastasize to the capsule and stroma, blood vessels, and distant organs in humans (Tlemcani et al 2010) and dogs (Simko et al 2003), while other authors suggest that apocrine adenocarcinomas invade lymphatics without any distant metastasis (Kalaher et al 1990, Haziroglu et al 2012, Jark et al 2015). Despite the information available in other species, neither blood nor lymphatic vessel invasion was observed in histological specimens from our horse, which is similar to what was observed in previous reports (Cihocki et al 2007, Ghasami et al 2017). Although spread via the lymphatic route cannot be completely ruled out in our case, the lack of supporting evidence of spread via blood or lymphatics in horses and the lack of vessel invasion in the histological samples of this case support the possibility of de novo development of multiple tumours.

Treating equine skin neoplasia has been historically challenging, and unresponsiveness to treatment, tumour re-growth and metastasis are frequent situations affecting the effectiveness of the treatment and the outcomes (Hewes and Sullins 2009). Cisplatin administration, either mixed with sterile sesame oil or slow-release biodegradable beads, has shown good outcomes after treatment in different types of equine skin tumours (Hewes and Sullins 2006), however, treatment options for epitrichial sweat gland carcinomas have been limited mostly to surgical excision and cryosurgery (Scott and Miller 2011 a , Ghasami et al 2017). Recently, Cihocki et al (2007), after a failed treatment with cisplatin, used an FDA approved topical 
cream (Imiquimod) to treat a horse presenting sweat gland carcinomas. However, Imiquimod cream showed some side effects throughout the treatment course such as marked inflammatory response at the application site and only $50 \%$ efficacy (Cihocki et al 2007). Adverse side effects associated with topical imiquimod were also described in a sarcoid pilot study, however, the efficacy of the drug appeared to be higher for this type of neoplasia (Nogueira et al 2006). The horse in this report was treated with a cryotherapy system that contains dimethyl ether, propane and isobutane (Pointts $®$ ), and is commonly used for the treatment of verrucous lesions in humans. The use of this product appeared safe and was not associated with significant side effects. The remaining nodules (10) were significantly smaller after one treatment with cryotherapy. A second and third treatment with cryotherapy as labelled for humans was indicated to achieve full remission of tumours, but the owner declined to continue with therapy due to the good response to initial treatment, musculoskeletal soundness, and return to full work. Considering the efficacy of the cryotherapy to resolve and/or shrink this type of tumour and the anti-tumour properties previously described for Imiquimod 5\%, a combined therapy could be considered to achieve full remission of this type of carcinoma.

In conclusion, epitrichial sweat gland carcinomas should be considered as a differential diagnosis when tumours with normal, alopecic and/or ulcerated skin are present in the pastern, fetlock, and even near the carpal region. This type of tumour does not normally cause lameness, nonetheless, when ulcerated lesions are present, they can get infected and cause musculoskeletal discomfort. The few cases described so far have demonstrated this type of neoplasia to be locally invasive but without resulting in metastasis as stated in other species. Treating skin tumours has been historically challenging, however for this specific type of tumour, surgical excision and cryotherapy with dimethyl ether, propane and isobutane preparation appear to be effective without side effects attributable to the treatment. Finally, further studies are needed to elucidate the pathways of spread throughout the body for this type of tumour, the mechanism of which is yet unknown in horses.

\section{REFERENCES}

Anderson WI, Scott DW, Crameri FM. 1990. Two rare cutaneous neoplasms in horses: Apocrine gland adenocarcinoma and carcinosarcoma. Cornell Vet 80, 339-345.

Burns RE, Pesavento PA, McElliott VR, Ortega J, Affolter VK. 2011. Glomus tumours in the skin and subcutis of three horses. Vet Dermatol 22, 225-231.

Cihocki LM, Divers TJ, Johnson AL, Warren AL, Schramme M, et al. 2007. A case of multiple epitrichial sweat gland ductal carcinomas in a horse. Vet Dermatol 18, 134-137.

Ghasemi S, Sardari K, Movassaghi AR. 2017. Apocrine sweat gland ductal carcinoma in a 5-year-old Arabian stallion. Comp Clin Pathol 26, 1399-1402.

Haziroglu R, Haligur M, Keles H. 2012. Histopathological and immunohistochemical studies of apocrine sweat gland adenocarcinomas in cats. Vet Comp Oncol 12, 85-90.

Hewes CA, Sullins KE. 2006. Use of cisplatin-containing biodegradable beads for treatment of cutaneous neoplasia in equidae: 59 cases (2000-2004). J Am Vet Med Assoc 229, 1617-1622.

Hewes CA, Sullins KE. 2009. Review of the treatment of equine cutaneous neoplasia. AAEP Proceedings 55, 386-393.

Jark PC, Huppes RR, Sierra OR, Maria BP, Raposo TMM, et al. 2015. Carcinoma de glándulas apocrinas con compromiso de vasos linfáticos de la dermis: reporte de dos casos Arch Med Vet 47, 251-254.

Kalaher KM, Anderson WI, Scott DW. 1990. Neoplasms of the sweat gland in 44 dogs and 10 cats. Vet Rec 127, 400-403.

Lykkjen S, Strand E, Haga HA, Lie KI. 2006. Radical surgical resection of locally invasive oro-cutaneous tumors in the buccal region of 2 horses. Vet Surg 35, 319-323.

Nogueira SA, Torres SM, Malone ED, Diaz SF, Jessen C, et al. 2006. Efficacy of imiquimod $5 \%$ cream in the treatment of equine sarcoids: a pilot study. Vet Dermatol 17, 259-265.

Scott DW, Miller WH. 2011 a . Neoplasm, cyst, hamartomas, and keratoses. In: Equine Dermatology. $2^{\text {nd }}$ ed. Saunders Elsevier, Maryland Heights, USA, Pp 468-516.

Scott DW, Miller WH. 2011 ${ }^{\text {b }}$ Structure and function of the skin. In: Equine Dermatology. $2^{\text {nd }}$ ed. Saunders Elsevier, Maryland Heights, USA, Pp 1-34.

Simko E, Wilcock BP, Yager JA. 2003. A retrospective study of 44 canine apocrine sweat gland adenocarcinomas. Can Vet J 44, 38-42.

Slovis NM, McEntee MC, Fairley RA, Galuppo LD, Théon AP. 2001. Equine basal cell tumors: 6 cases (1985-1999). J Vet Intern Med $15,43-46$.

Tlemcani K, Levine D, Smith RV, Brandwein-Gensler M, Staffenberg DA, et al. 2010. Metastatic apocrine carcinoma of the scalp: prolonged response to systemic chemotherapy. J Clin Oncol 28, e412-e414. 